\title{
Advanced recycling process for waste plastics based on physical degradation theory and its stability
}

\author{
Aya Tominaga $^{1} \cdot$ Hiroshi Sekiguchi $^{2} \cdot$ Ryoko Nakano $^{2} \cdot$ Shigeru Yao $^{1,2} \cdot$ Eiichi Takatori $^{3}$
}

Received: 22 February 2017 / Accepted: 8 August 2018 / Published online: 23 August 2018

(c) The Author(s) 2018

\begin{abstract}
In this study, we evaluated the mechanical properties of pre-consumer recycled polypropylene thin films molded at more various temperatures, times and cooling conditions. We also evaluated the durability toward UV irradiation, and the effects of re-molding and annealing on the stability of these improved mechanical properties. The results of this study show that the mechanical properties of recycled polypropylene can be greatly improved to be almost the same as those of virgin polypropylene by choosing suitable molding condition. The mechanically improved samples also show enhanced durability towards UV. Annealing is also carried out to stabilize the mechanical properties that had been improved by quenching.
\end{abstract}

Keywords Pre-consumer recycled polypropylene (pre-RPP) - The heat treatment condition · The cooling conditions . Annealing process $\cdot$ The stabilization of mechanical properties

\section{Introduction}

In Japan, most waste plastics from households are currently collected and recycled by one of three methods: energy recovery (thermal recycling, chemical recycling, and material recycling) [1]. Energy recovery recovers thermal energy by combustion, and is relatively simple and effective. However, from an environmental perspective, energy recovery should be the last option. Chemical recycling requires considerable amounts of energy and very complex processes and, therefore, is not widely used. An ideal approach would be to repeat material recycling several times, and to use energy recovery only for materials that are difficult to reuse or when material recycling is impractical. However, as shown in Fig. 1, the proportion of material-recycled plastic has remained at about $30 \%$ for the past 13 years [2]. This is

Aya Tominaga

a-tominaga@nissan-arc.co.jp; shyao@fukuoka-u.ac.jp

1 Graduate School of Energy and Environmental Systems Engineering, Fukuoka University, 8-19-1 Nanakuma, Jonan, Fukuoka, Fukuoka Prefecture 814-0180, Japan

2 Faculty of Engineering, Department of Chemical Engineering, Fukuoka University, 8-19-1 Nanakuma, Jonan, Fukuoka, Fukuoka Prefecture 814-0180, Japan

3 TOSOH Analysis and Research Center Co. LTD., 1-8, Kasumi, Yokkaichi, Mie 510-8540, Japan because the physical properties of products made from material-recycled plastics are inferior to those of products made from virgin plastics. Therefore, material-recycled plastics are only used in low-value-added products and have limited applications.

The poor physical properties of material-recycled plastics are believed to be due to the chemical degradation that results from the heat, ultraviolet light or oxidation in the recycling process. Such chemical degradation is thought to be irreversible because it is associated with the breaking of molecular chains [3-5].

However, our recent research indicated that the molecular properties of material-recycled plastics can be restored to the same levels as those seen in virgin plastics $[6,7]$. This means that the main factor in the poor physical properties of material-recycled plastics is physical degradation. Physical degradation arises from changes in the crystal structures and internal structures of polymers, which are caused by deformation during fabrication of the material [7-21].

In the recycled plastic case, from our previous study, the physical degradation was caused by the number decrease of tie molecules. Moreover, our previous report showed that physical properties can be recovered through proper selection of the molding conditions [22-24].

In this study, we investigated the dependence of the mechanical properties of material-recycled plastics on higher temperature processing conditions. We found that 
Fig. 1 The ratio of thermal, chemical and material recycling for 13 years [2]. Blue: Thermal Recycling, Green: Chemical Recycling, Red: Material Recycling. (Color figure online)

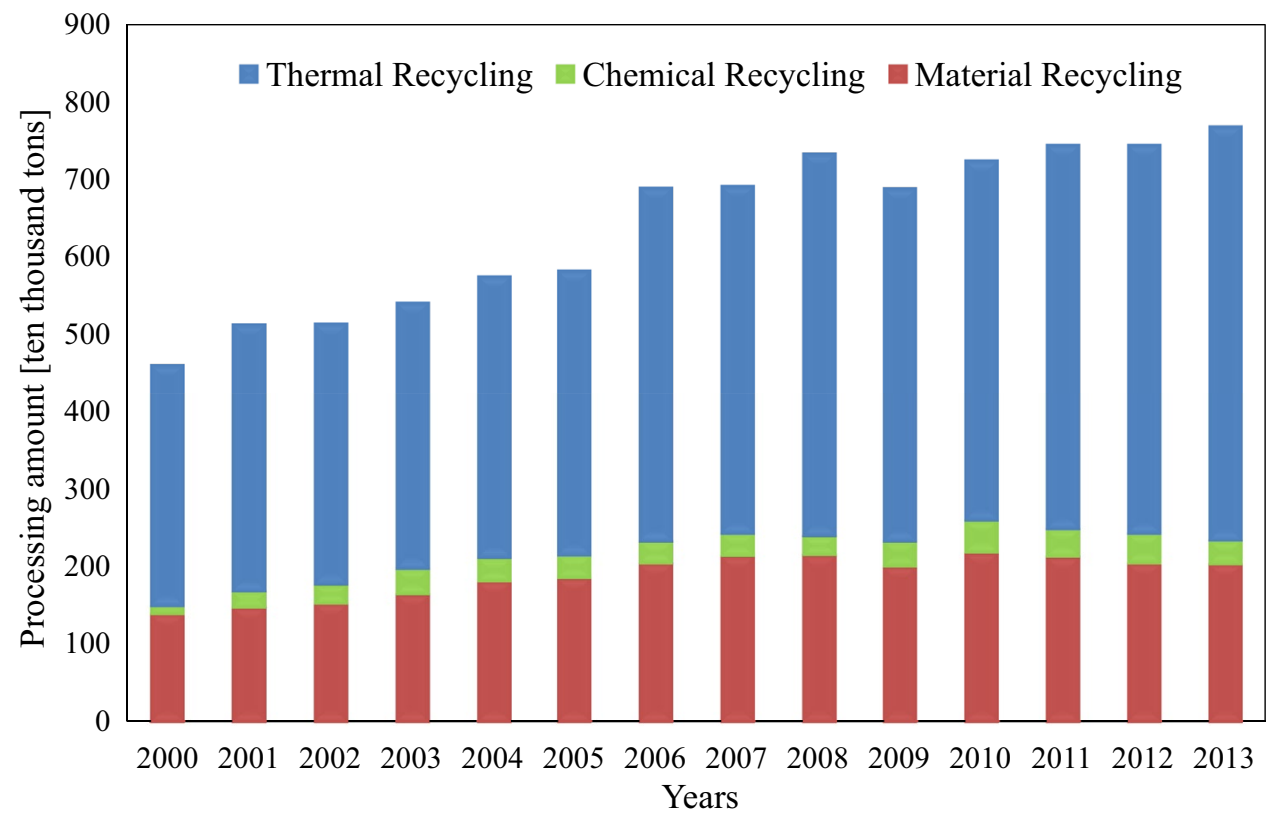

materials that were melt-processed at a temperature higher than that used in the conventional molding condition, and subsequently quenched, had improved physical properties compared to virgin materials that were formed under standard molding conditions. We also investigated the stability of the enhanced mechanical properties and a method of stabilization.

\section{Experiment}

\section{Samples and molding conditions of test thin films}

Transparent, injection-molding-grade virgin isotactic polypropylene (VPP) and pre-consumer recycled polypropylene (Pre-RPP) were used in the experiments. Pre-RPP was made by pelletization of byproducts (such as runner and gate part) of injection-molded VPP, such as the runners generated during injection molding. Detailed molecular properties, including the molecular weight, molecular weight distribution, density, and the melt flow ratio
(MFR), of these two materials were confirmed to be almost the same [22, 23, 25].

Thin films were made from pellets of VPP and Pre-RPP by a press molding machine (MH-10; IMOTO Machinery Co. Ltd.). For the formation of the thin films, the hot press temperatures are $210{ }^{\circ} \mathrm{C}, 230{ }^{\circ} \mathrm{C}$, and $250{ }^{\circ} \mathrm{C}$, hot press times are $2 \mathrm{~min}, 6 \mathrm{~min}$, and $10 \mathrm{~min}$. Figure 2 shows the process of film molding. Molded films were cooled at room temperature (Slow Cooled : SC) or in an ice-water bath (quench : Q).

To investigate the effect of annealing and re-molding of the mechanically improved films, we also used a press molding machine. Figure 3 a shows how annealing was carried out. A thin film was placed between releasing films and then put it between stainless steel plates and annealed. In this study, annealing was performed at $65{ }^{\circ} \mathrm{C}$ for $2 \mathrm{~h}$. Figure $3 \mathrm{~b}$ shows the re-molding process. The thin film was divided into 4 square pieces and they were overlaid and press molded at $210^{\circ} \mathrm{C}, 2 \mathrm{~min}, \mathrm{SC}$.
Fig. 2 The process of film molding

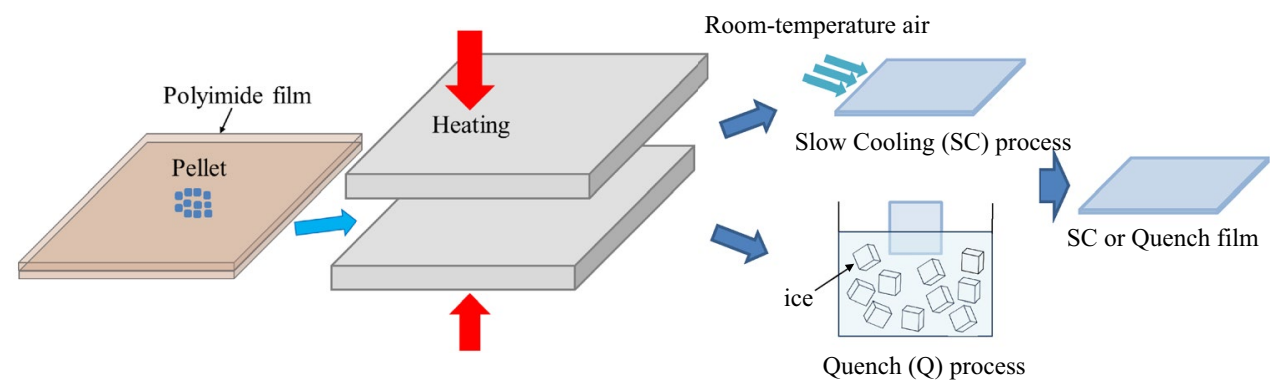


Fig. 3 The process of annealing and re-molding process after annealing. a Process of annealing, $\mathbf{b}$ re-molding process after annealing
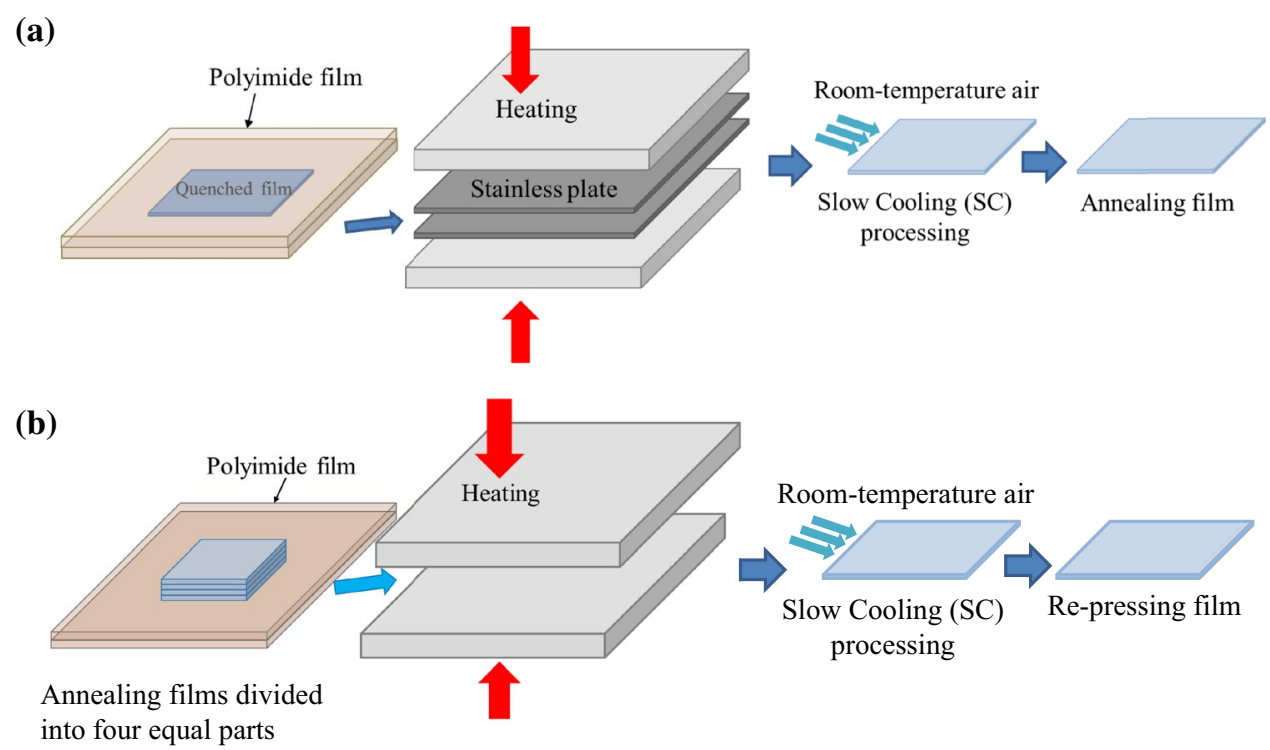

\section{Measurement of tensile properties}

The tensile test specimen was punched from thin films fabricated under various press mold conditions. The length of the specimen is $8 \pm 0.5 \mathrm{~mm}$ and the width is $2 \pm 0.2 \mathrm{~mm}$ according to JIS K $71132(1 / 3)$. The thickness of the thin films used in the tensile tests was about $60-100 \mu \mathrm{m}$. Five specimens were used for each tensile test. Tensile tests were carried out at $26.0{ }^{\circ} \mathrm{C}$ and $41.5 \% \mathrm{RH}$. The elongation rate was $5 \mathrm{~mm} /$ min. A screw-type uniaxial tester (LSC-02/30-2; Tokyo Testing Machine Company) was used for the evaluation.

Toughness was evaluated from the area surrounded by the load-displacement curve by the initial cross-section of the specimen.

\section{Crystallinity evaluation by DSC}

To investigate the crystallinity of thin films, we used DSC measurement. The sample mass was approximately 4-6 mg. A DSC3100 from Mac Science was employed for the melting point measurements, and a heating rate of $5^{\circ} \mathrm{C} / \mathrm{min}$ was used. The heat of fusion of the polypropylene crystal used in this study was $210.0 \mathrm{~J} / \mathrm{g}$.

\section{Durability evaluation by UV irradiation}

To investigate the UV stability of virgin film and the mechanical properties of improved films, we examined the UV durability. The UV durability machine was an EYE SUPER UV TESTER SUV-W161 (IWASAKI ELECTRIC CO., LTD) [6, 26]. The temperature near films in the machine was about $63-64^{\circ} \mathrm{C}$. The irradiation time was $2 \mathrm{~h}$, $6 \mathrm{~h}$, and $12 \mathrm{~h}$. After the UV irradiation treatment, we measured the toughness of the irradiated films.

\section{Results and discussion}

\section{Tensile properties}

As described in our previous report, we evaluated the mechanical properties and internal structures of thin films of VPP and Pre-RPP that were molded at various temperatures, times, and cooling conditions [22-24]. In this investigation, the thin film specimens used for the evaluation of mechanical properties were molded at temperatures of 230 or $250{ }^{\circ} \mathrm{C}$, mold times of $2 \mathrm{~min}, 6 \mathrm{~min}$, or $10 \mathrm{~min}$, and the quench condition. Table 1 summarizes the yield stress, Young's modulus, fracture elongation, tensile fracture energy, and breaking stress. As shown in Table 1, there was not much difference in the yield stress or Young's modulus between Pre-RPP thin films and VPP film molded at the standard condition $\left(210^{\circ} \mathrm{C}, 2 \mathrm{~min}, \mathrm{SC}\right)$. The fracture elongation and tensile fracture energy were significantly different and greatly inferior to those of VPP. However, the tensile properties of quenched samples were significantly improved. Conversely, quenched Pre-RPP specimens molded at $210^{\circ} \mathrm{C}$ showed ductility even with a mold time of $2 \mathrm{~min}$. Moreover, Pre-RPP thin films under the quench condition showed high fracture elongation and tensile fracture energy under all mold temperatures and times. Young's modulus is slightly low under the $\left(210^{\circ} \mathrm{C}, 2 \mathrm{~min}\right.$, quench) and $\left(210^{\circ} \mathrm{C}, 6 \mathrm{~min}\right.$, quench) conditions, however, in the other quenched conditions, the Young's modulus is higher than the VPP $\left(210^{\circ} \mathrm{C}\right.$, 2 min, SC) condition. This indicates that molding at high temperature and quenching improves the tensile property to a level comparable to that of VPP.

Figure 4 shows the results of the tensile property tests for VPP and Pre-RPP thin films. The inside figure is the details of early stage of the tensile test. Difference in 
Table 1 Mechanical properties of the tensile test standard-condition VPP, standard-condition Pre-RPP, and quench-condition Pre-RPP

\begin{tabular}{|c|c|c|c|c|c|}
\hline Sample & $\begin{array}{l}\text { Tensile fracture } \\
\text { elongation }(\mathrm{mm})\end{array}$ & $\begin{array}{l}\text { Tensile fracture } \\
\text { energy }\left(\mathrm{MJ} / \mathrm{m}^{2}\right)\end{array}$ & Tensile fracture stress $(\mathrm{Pa})$ & Yield point $(\mathrm{Pa})$ & Young's modulus $(\mathrm{Pa})$ \\
\hline VPP $210{ }^{\circ} \mathrm{C} 2 \mathrm{~min}, \mathrm{SC}$ & $114.9 \pm 0.71$ & $2.51 \pm 0.034$ & $3.0 \pm 0.038 \times 10^{7}$ & $2.4 \pm 0.036 \times 10^{7}$ & $3.0 \pm 0.073 \times 10^{8}$ \\
\hline Pre-RPP $210{ }^{\circ} \mathrm{C} 2 \mathrm{~min}, \mathrm{SC}$ & $11.1 \pm 3.24$ & $0.20 \pm 0.059$ & $7.9 \pm 1.21 \times 10^{6}$ & $2.5 \pm 0.015 \times 10^{7}$ & $4.4 \pm 0.045 \times 10^{8}$ \\
\hline Pre-RPP $210^{\circ} \mathrm{C} 2 \mathrm{~min}, \mathrm{Q}$ & $65.6 \pm 8.24$ & $1.10 \pm 0.15$ & $2.0 \pm 0.098 \times 10^{7}$ & $1.8 \pm 0.012 \times 10^{7}$ & $1.9 \pm 0.16 \times 10^{8}$ \\
\hline Pre-RPP $210^{\circ} \mathrm{C} 6 \mathrm{~min}, \mathrm{Q}$ & $78.6 \pm 4.57$ & $1.41 \pm 0.10$ & $2.2 \pm 0.091 \times 10^{7}$ & $2.1 \pm 0.0090 \times 10^{7}$ & $2.4 \pm 0.13 \times 10^{8}$ \\
\hline Pre-RPP $210{ }^{\circ} \mathrm{C} 10 \mathrm{~min}, \mathrm{Q}$ & $47.7 \pm 7.91$ & $0.79 \pm 0.14$ & $1.4 \pm 0.050 \times 10^{7}$ & $1.9 \pm 0.035 \times 10^{7}$ & $3.0 \pm 0.035 \times 10^{8}$ \\
\hline Pre-RPP $230^{\circ} \mathrm{C} 2 \mathrm{~min}, \mathrm{Q}$ & $43.2 \pm 4.79$ & $0.86 \pm 0.15$ & $2.0 \pm 0.21 \times 10^{7}$ & $3.2 \pm 0.072 \times 10^{7}$ & $3.7 \pm 0.39 \times 10^{8}$ \\
\hline Pre-RPP $230^{\circ} \mathrm{C} 6 \mathrm{~min}, \mathrm{Q}$ & $68.3 \pm 7.88$ & $1.91 \pm 0.23$ & $3.0 \pm 0.26 \times 10^{7}$ & $3.2 \pm 0.029 \times 10^{7}$ & $3.7 \pm 0.38 \times 10^{8}$ \\
\hline Pre-RPP $230{ }^{\circ} \mathrm{C} 10 \mathrm{~min}, \mathrm{Q}$ & $50.9 \pm 9.56$ & $1.47 \pm 0.29$ & $2.4 \pm 0.15 \times 10^{7}$ & $3.3 \pm 0.024 \times 10^{7}$ & $3.8 \pm 0.33 \times 10^{8}$ \\
\hline Pre-RPP $250{ }^{\circ} \mathrm{C} 2 \mathrm{~min}, \mathrm{Q}$ & $55.1 \pm 6.64$ & $1.48 \pm 0.19$ & $2.6 \pm 0.11 \times 10^{7}$ & $3.1 \pm 0.054 \times 10^{7}$ & $3.5 \pm 0.29 \times 10^{8}$ \\
\hline Pre-RPP $250^{\circ} \mathrm{C} 6 \mathrm{~min}, \mathrm{Q}$ & $36.8 \pm 7.60$ & $1.09 \pm 0.23$ & $2.2 \pm 0.26 \times 10^{7}$ & $3.6 \pm 0.013 \times 10^{7}$ & $3.6 \pm 0.47 \times 10^{8}$ \\
\hline Pre-RPP $250{ }^{\circ} \mathrm{C} 10 \mathrm{~min}, \mathrm{Q}$ & $70.3 \pm 7.82$ & $2.07 \pm 0.24$ & $3.2 \pm 0.11 \times 10^{7}$ & $3.4 \pm 0.029 \times 10^{7}$ & $3.4 \pm 0.36 \times 10^{8}$ \\
\hline
\end{tabular}
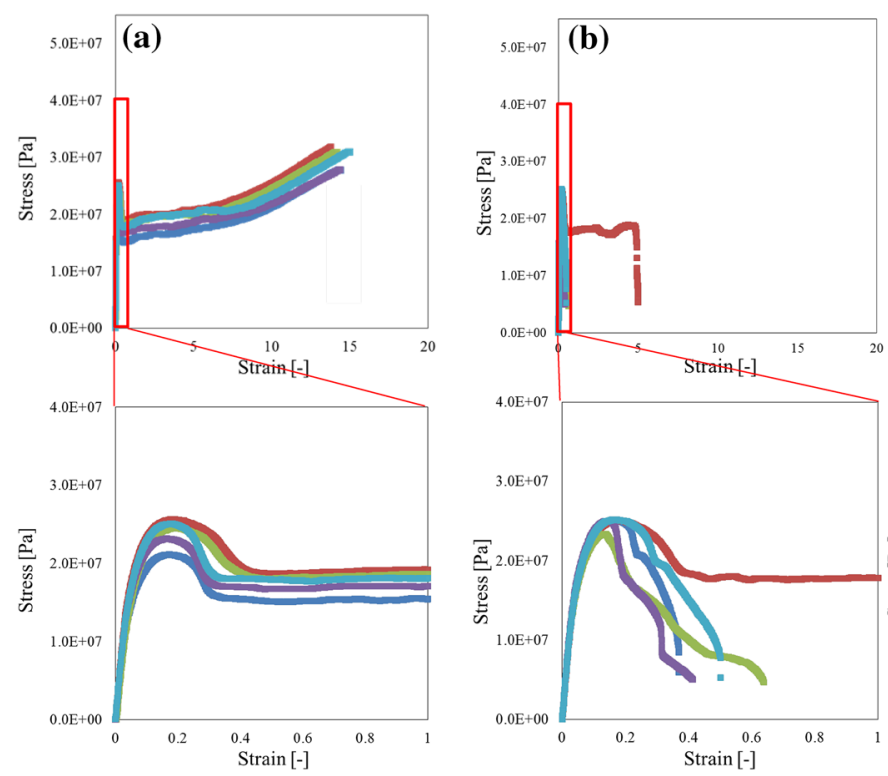

Fig. 4 Stress-strain curves of quenched Pre-RPP samples. In all the tensile tests, 5 test pieces were used (difference in color means each test specimen of the condition). The lower figures $\left({ }^{*}-\mathrm{E}\right)$ are the

color of the figure means each test specimen result of the condition. Figure $4 \mathrm{a}$ shows the results for VPP molded at $210{ }^{\circ} \mathrm{C}, 2 \mathrm{~min}, \mathrm{SC}$. All samples are very ductile. Figure $4 \mathrm{~b}$ shows the results for Pre-RPP molded at $210^{\circ} \mathrm{C}, 2 \mathrm{~min}$, SC. Most of the samples were brittle. Figure $4 \mathrm{c}$ shows the results for Pre-RPP molded at $230{ }^{\circ} \mathrm{C}, 10 \mathrm{~min}$, quench. The samples showed high breaking stress and large elongation. Figure $4 \mathrm{~d}$ shows the results for Pre-RPP molded at $250{ }^{\circ} \mathrm{C}$, $10 \mathrm{~min}$, quench. Very large elongation and good ductility were observed, as well as very high breaking stress.

Figure 5 shows photo image of the test pieces after the tensile strength test of Pre-RPP. The mechanical properties
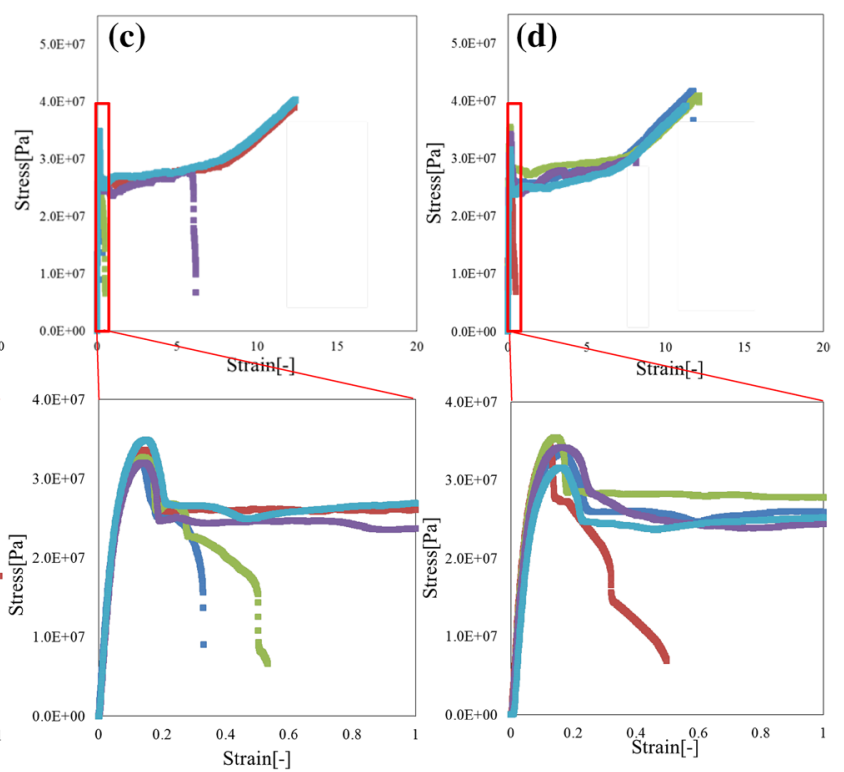

enlarged figures at the early stage of the tensile test. a VPP $210^{\circ} \mathrm{C}$, $2 \mathrm{~min}, \mathrm{SC}, \mathbf{b}$ Pre-RPP $210^{\circ} \mathrm{C}, 2 \mathrm{~min}, \mathrm{SC}$, c Pre-RPP $230{ }^{\circ} \mathrm{C}, 10 \mathrm{~min}$, quench, $\mathbf{d}$ Pre-RPP $250^{\circ} \mathrm{C}, 10$ min quench

of Pre-RPP improved by changing hot pressing and cooling conditions.

Figure 6 shows a comparison of the tensile fracture energies of two cooling conditions ( $\mathrm{SC}$ and quench), various compression temperatures $\left(210{ }^{\circ} \mathrm{C}, 230{ }^{\circ} \mathrm{C}, 250{ }^{\circ} \mathrm{C}\right)$ and compression times ( $2 \mathrm{~min}, 6 \mathrm{~min}, 10 \mathrm{~min}$ ). The bar graphs show the average value and the black error bars show standard deviation of tensile fracture energy. In the SC and $210{ }^{\circ} \mathrm{C}$ case, the tensile fracture energy increased with increasing the compression time. However, the average tensile fracture energies of all the Pre-RPP specimens in the SC condition were very low compared to the VPP value. On the other 
Fig. 5 Image of the test pieces after the tensile test of Pre-RPP. a Pre-RPP $210^{\circ} \mathrm{C} 2 \mathrm{~min} \mathrm{SC}$, b Pre-RPP $2300^{\circ} \mathrm{C} 10 \mathrm{~min} \mathrm{Q}, \mathbf{c}$ Pre-RPP $250{ }^{\circ} \mathrm{C} 10 \mathrm{~min} \mathrm{Q}$ (a)

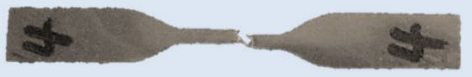

(b) 6

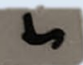

(c)

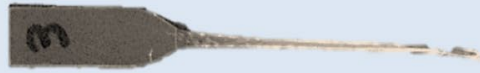

Fig. 6 Tensile fracture energy for each tensile test

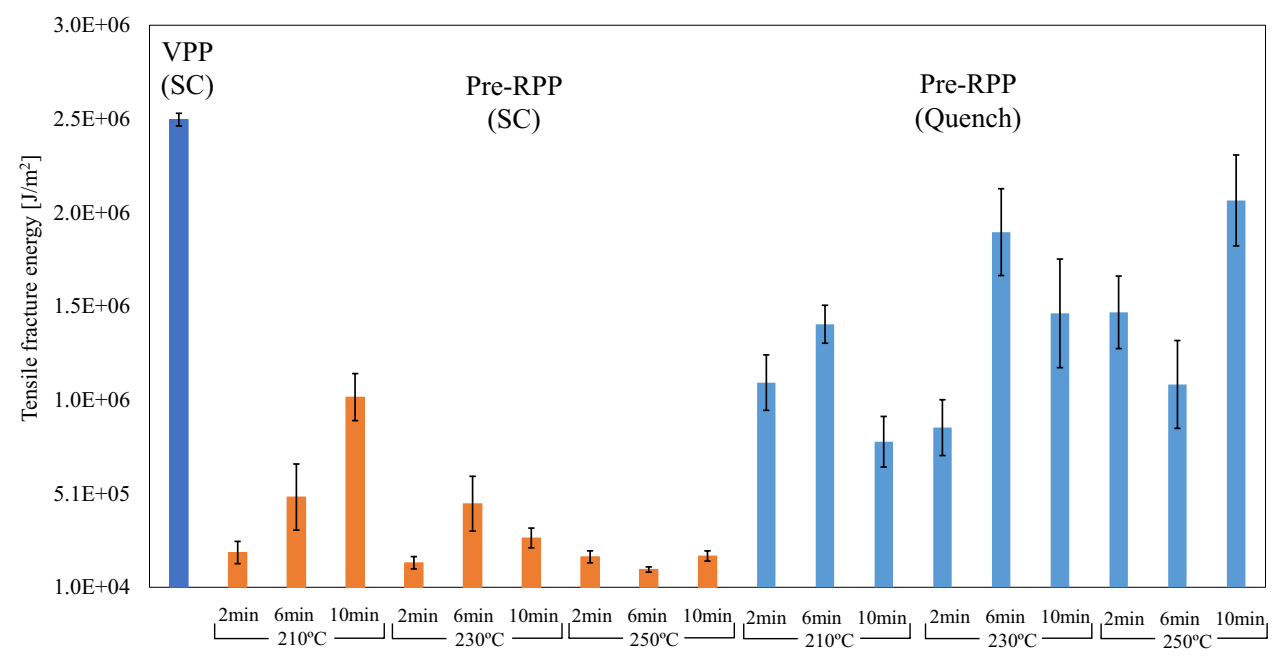

hand, in the Quench condition, the values of tensile fracture energy are significantly increased. Also, there are some slight tendencies that with increasing the compression time, the tensile fracture energy increases especially at $230{ }^{\circ} \mathrm{C}$ case and $250{ }^{\circ} \mathrm{C}$ case. In particular, specimens under $250{ }^{\circ} \mathrm{C}$, $10 \mathrm{~min}$, quench, showed almost the same fracture energy as VPP. This result indicates that, through the selection of suitable molding conditions (in this case, high temperature, long compression time, and Quench), Pre-RPP samples can show mechanical properties comparable to those of VPP.

Table 2 shows the crystallinity derived from the DSC measurement. The crystallinity of VPP and Pre-RPP (SC condition) samples was around $31 \%$, on the other hand Pre-RPP quenched samples $\left(210^{\circ} \mathrm{C}, 2 \mathrm{~min}, \mathrm{Q}\right),\left(210^{\circ} \mathrm{C}\right.$, $6 \mathrm{~min}, \mathrm{Q})$, and $\left(250^{\circ} \mathrm{C}, 6 \mathrm{~min}, \mathrm{Q}\right)$ were around $27 \%$. However, the tensile properties of these samples did not coincide with these values. As an example, the crystallinity of Pre-RPP $\left(210^{\circ} \mathrm{C}, 2 \mathrm{~min}, \mathrm{SC}\right)$ is same as the VPP, but the former Young's modulus is much higher than the latter; on the other hand, the crystallinity of Pre-RPP $\left(250{ }^{\circ} \mathrm{C}, 10 \mathrm{~min}, \mathrm{Q}\right)$ is lower than the VPP, but the former
Table 2 Degree of crystallinity of VPP and Pre-RPP under various conditions

\begin{tabular}{ll}
\hline Sample & $\begin{array}{l}\text { Degree of } \\
\text { crystallinity } \\
(\%)\end{array}$ \\
\hline VPP $210^{\circ} \mathrm{C} 2 \mathrm{~min}, \mathrm{SC}$ & 31 \\
Pre-RPP $210^{\circ} \mathrm{C} 2 \mathrm{~min}, \mathrm{SC}$ & 31 \\
Pre-RPP $210^{\circ} \mathrm{C} 6 \mathrm{~min}, \mathrm{SC}$ & 34 \\
Pre-RPP $210^{\circ} \mathrm{C} 2 \mathrm{~min}, \mathrm{Q}$ & 26 \\
Pre-RPP $210^{\circ} \mathrm{C} 6 \mathrm{~min}, \mathrm{Q}$ & 28 \\
Pre-RPP $250^{\circ} \mathrm{C} 10 \mathrm{~min}, \mathrm{Q}$ & 27 \\
\hline
\end{tabular}

Young's modulus is higher than the latter. Especially, the tensile fracture energy does not depend on the crystallinity. These results also indicate that the difference of the tensile properties comes not only from the crystallinity but the difference of these inner structures. 


\section{Durability under UV irradiation}

Figure 7 shows the UV irradiation time dependence of tensile fracture energy. The horizontal axis shows the duration of irradiation in hours and the vertical axis shows the elongation fracture energy. Figure $7 \mathrm{a}$ shows the results for VPP thin film molded at the standard molding condition $\left(210^{\circ} \mathrm{C}, 2 \mathrm{~min}, \mathrm{SC}\right)$. The tensile fracture energy decreases gradually with an increase in the irradiation time. Figure $7 \mathrm{~b}$ shows the results for Pre-RPP thin film molded at the same conditions. The tensile fracture energy at time 0 is very low compared to that of VPP thin film. On the other hand, the UV irradiation time dependence of tensile fracture energy in the improved films in Fig. 7c $\left(210{ }^{\circ} \mathrm{C}, 2 \mathrm{~min}\right.$, Quench) and Fig. $7 \mathrm{~d}\left(210^{\circ} \mathrm{C} 6 \mathrm{~min}\right.$, Quench) is almost the same as that of VPP film. This result shows that by choosing a suitable molding condition the stability also increases.
Fig. 7 UV irradiation time dependence of elongation fracture energy. a VPP $210^{\circ} \mathrm{C}$ 2 min SC, b Pre-RPP $210^{\circ} \mathrm{C}$ 2 min SC, c Pre-RPP $210^{\circ} \mathrm{C}$ $2 \min \mathrm{Q}, \mathbf{d}$ Pre-RPP $210^{\circ} \mathrm{C}$ $6 \min \mathrm{Q}$
Fig. 8 Tensile fracture energies of various original films (molded by each temperature, time, and Q conditions) and after re-molding by $\left(210^{\circ} \mathrm{C}\right.$, 2 min SC) condition
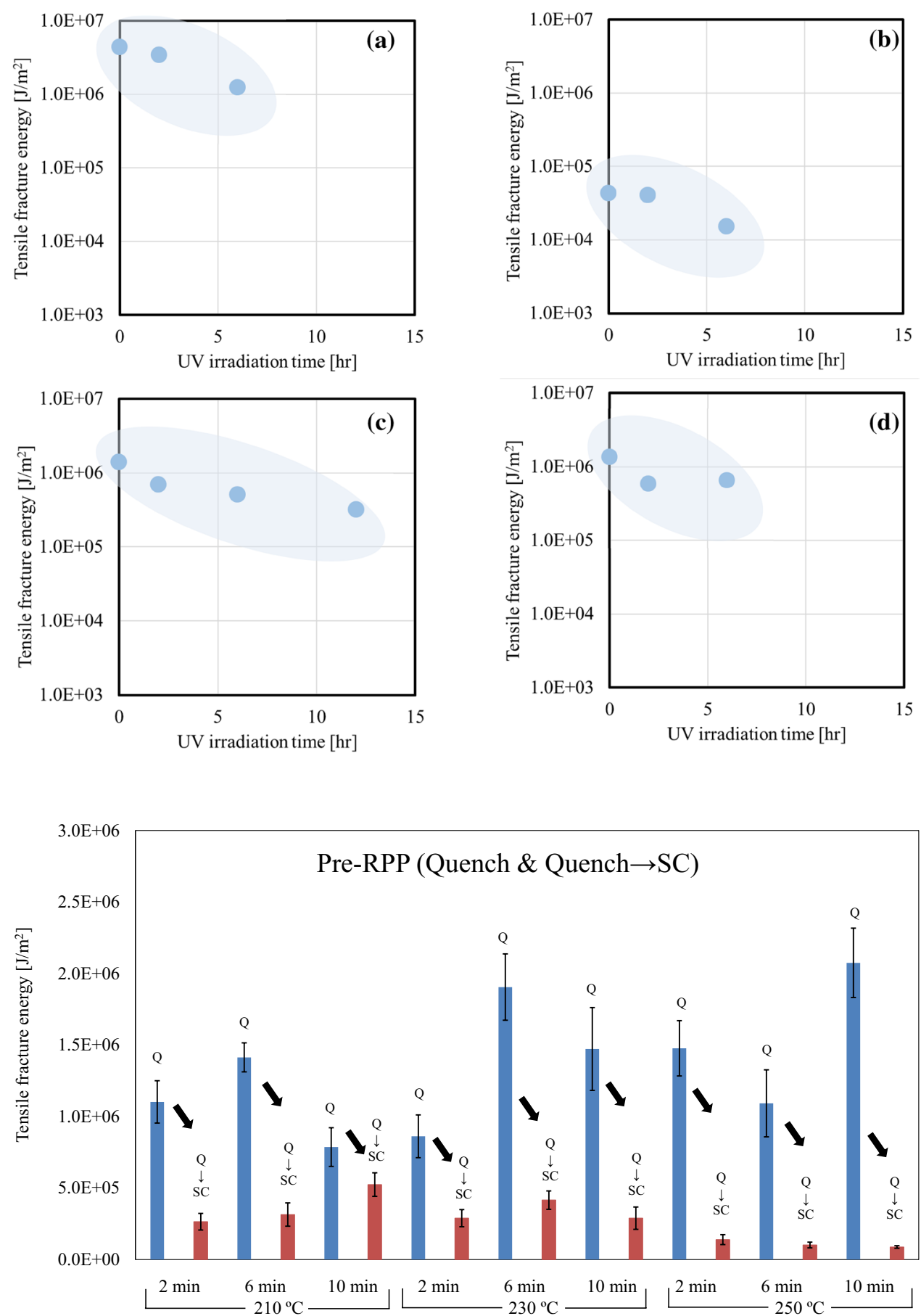
Table 3 Preparation conditions for test samples

\begin{tabular}{|c|c|}
\hline Sample & Process up to manufacture \\
\hline (A) & Pre-RPP $210^{\circ} \mathrm{C} 6 \mathrm{~min}, \mathrm{Q}$ \\
\hline (B) & Pre-RPP $210{ }^{\circ} \mathrm{C} 6 \mathrm{~min}, \mathrm{Q} \rightarrow 210^{\circ} \mathrm{C} 2 \mathrm{~min}, \mathrm{SC}$ \\
\hline (C) & Pre-RPP $210^{\circ} \mathrm{C} 6 \min , \mathrm{Q} \rightarrow 65^{\circ} \mathrm{C} 2 \mathrm{~h}$ annealing \\
\hline (D) & Pre-RPP $210^{\circ} \mathrm{C} 6 \mathrm{~min}, \mathrm{Q} \rightarrow 65^{\circ} \mathrm{C} 8 \mathrm{~h}$ annealing \\
\hline (E) & Pre-RPP $210{ }^{\circ} \mathrm{C} 6 \mathrm{~min}, \mathrm{Q} \rightarrow 65^{\circ} \mathrm{C} 2 \mathrm{~h}$ annealing $\rightarrow 210^{\circ} \mathrm{C} 2 \mathrm{~min}, \mathrm{SC}$ \\
\hline (F) & Pre-RPP $210^{\circ} \mathrm{C} 6 \mathrm{~min}, \mathrm{Q} \rightarrow 65^{\circ} \mathrm{C} 8 \mathrm{~h}$ annealing $\rightarrow 210^{\circ} \mathrm{C} 2 \mathrm{~min}, \mathrm{SC}$ \\
\hline
\end{tabular}

Table 4 Tensile test results

\begin{tabular}{lllll}
\hline $\begin{array}{l}\text { Sample (Pre- } \\
\text { RPP) }\end{array}$ & $\begin{array}{l}\text { Tensile fracture } \\
\text { elongation }(\mathrm{mm})\end{array}$ & $\begin{array}{l}\text { Tensile fracture } \\
\text { energy }\left(\mathrm{MJ} / \mathrm{m}^{2}\right)\end{array}$ & Yield stress $(\mathrm{Pa})$ & Young's modulus (Pa) \\
\hline (A) & $72.3 \pm 7.97$ & $1.52 \pm 0.18$ & $2.1 \pm 0.030 \times 10^{7}$ & $1.4 \pm 0.25 \times 10^{8}$ \\
$(\mathrm{~B})$ & $18.6 \pm 4.49$ & $0.31 \pm 0.081$ & $2.1 \pm 0.013 \times 10^{7}$ & $2.8 \pm 0.043 \times 10^{8}$ \\
(C) & $65.0 \pm 6.58$ & $1.33 \pm 0.16$ & $2.3 \pm 0.025 \times 10^{7}$ & $3.7 \pm 0.16 \times 10^{8}$ \\
(D) & $39.6 \pm 6.20$ & $0.88 \pm 0.15$ & $2.7 \pm 0.030 \times 10^{7}$ & $5.0 \pm 0.075 \times 10^{8}$ \\
(E) & $46.0 \pm 7.66$ & $1.00 \pm 0.19$ & $2.3 \pm 0.068 \times 10^{7}$ & $4.3 \pm 0.024 \times 10^{8}$ \\
(F) & $10.3 \pm 1.26$ & $0.21 \pm 0.030$ & $2.7 \pm 0.059 \times 10^{7}$ & $5.8 \pm 0.14 \times 10^{8}$ \\
\hline
\end{tabular}

The UV is believed to break the molecules between crystal lamella, [20] and the above results indicate that the number of tie molecules in a thin film of Pre-RPP molded at standard molding conditions is very low compared to that in VPP. However, the number of tie molecules in improved films of Pre-RPP is close to that in VPP. This result also indicates that the physical degradation and physical regeneration are much related with the number of tie molecules.

\section{Effects of re-molding and annealing on stability}

Figure 8 shows the transition of fracture elongation length between original and remolded results. The original values were obtained from thin films molded at various quench conditions. Re-molding was performed under the standard conditions $\left(210{ }^{\circ} \mathrm{C}, 2 \mathrm{~min}, \mathrm{SC}\right)$. As shown in this figure, the mechanical properties that had been improved under the quench conditions deteriorated after re-molding.

These results indicate that the excellent mechanical properties of materials prepared under the quench condition were lost after further heat treatment. Therefore, stabilizing the high performance is very important.

Annealing is a well-known method for stabilizing the inner structure of polymers [27-32]. Therefore, we evaluated the effects of annealing.

For the annealing investigation, we used a thin film molded at $210{ }^{\circ} \mathrm{C}, 6 \mathrm{~min}$, quench. Thin films made under this condition show very high fracture elongation and tensile fracture energy.

In Table 3, we summarize the film-preparation conditions. Table 4 shows the tensile test results for all of the specimens. From the results, the original film was very ductile and fracture elongation was also large. The annealed film (C) was ductile and showed almost same value compared to the original film (A). However, the annealed film (D) became brittle. The annealed-remolded film (E) had the same mechanical properties as the original film (A) and the annealed film (C). This result indicates that annealing is effective for stabilizing improved mechanical properties. However, the annealed-remolded film (F) showed poor mechanical properties. From the

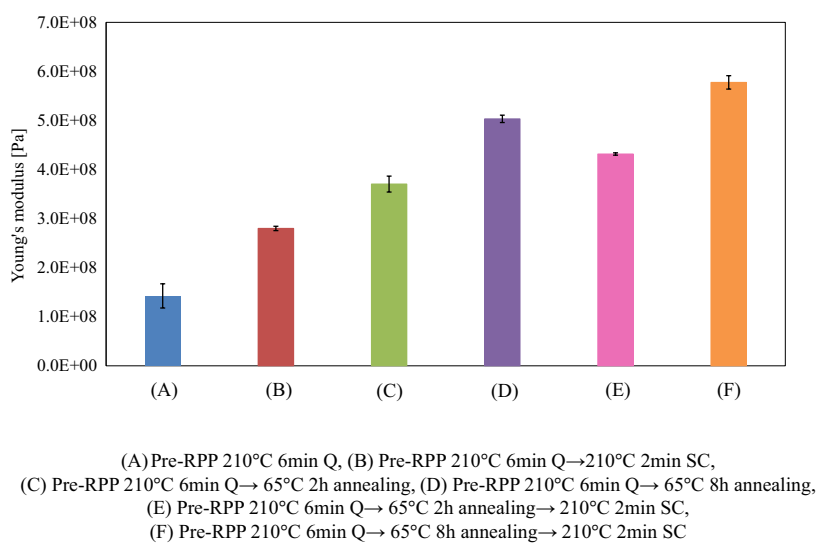

Fig. 9 A comparison of young's modulus of the samples. a Pre-RPP $210{ }^{\circ} \mathrm{C} 6 \min \mathrm{Q}$, b Pre-RPP $210^{\circ} \mathrm{C} 6 \min \mathrm{Q} \rightarrow 210^{\circ} \mathrm{C} 2 \min \mathrm{SC}, \mathbf{c}$ Pre-RPP $210^{\circ} \mathrm{C} 6$ min $\mathrm{Q} \rightarrow 65^{\circ} \mathrm{C} 2 \mathrm{~h}$ annealing, d Pre-RPP $210^{\circ} \mathrm{C}$ $6 \min \mathrm{Q} \rightarrow 65^{\circ} \mathrm{C} 8 \mathrm{~h}$ annealing, e Pre-RPP $210^{\circ} \mathrm{C} 6 \mathrm{~min} \mathrm{Q} \rightarrow 65^{\circ} \mathrm{C}$ $2 \mathrm{~h}$ annealing $\rightarrow 210{ }^{\circ} \mathrm{C} 2 \mathrm{~min} \mathrm{SC}$, f Pre-RPP $210{ }^{\circ} \mathrm{C} 6 \mathrm{~min} \mathrm{Q} \rightarrow$ $65^{\circ} \mathrm{C} 8 \mathrm{~h}$ annealing $\rightarrow 210^{\circ} \mathrm{C} 2 \mathrm{~min} \mathrm{SC}$ 
Fig. 10 Image of the test pieces after the tensile test. The samples were prepared under the conditions shown in Table 3. a Pre-RPP $210^{\circ} \mathrm{C} 6$ min Q, b Pre$\mathrm{RPP} 210{ }^{\circ} \mathrm{C} 6 \min \mathrm{Q} \rightarrow 210^{\circ} \mathrm{C}$ 2 min SC, c Pre-RPP $210^{\circ} \mathrm{C}$ $6 \min \mathrm{Q} \rightarrow 65^{\circ} \mathrm{C} 2 \mathrm{~h}$ annealing, d Pre-RPP $210^{\circ} \mathrm{C} 6$ min $\mathrm{Q} \rightarrow$ $65^{\circ} \mathrm{C} 8 \mathrm{~h}$ annealing, e Pre-RPP $210{ }^{\circ} \mathrm{C} 6 \min \mathrm{Q} \rightarrow 65^{\circ} \mathrm{C} 2 \mathrm{~h}$ annealing $\rightarrow 210^{\circ} \mathrm{C} 2 \mathrm{~min} \mathrm{SC}$, f Pre-RPP $210^{\circ} \mathrm{C} 6 \mathrm{~min} \mathrm{Q} \rightarrow$ $65^{\circ} \mathrm{C} 8 \mathrm{~h}$ annealing $\rightarrow 210^{\circ} \mathrm{C}$ 2 min SC
(A)

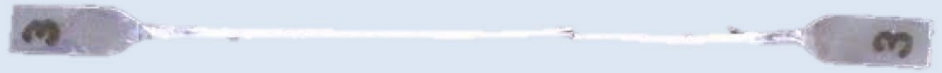

(B)

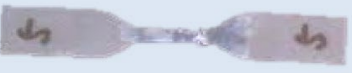

(C)

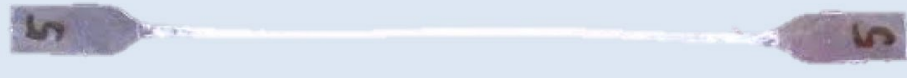

(D)

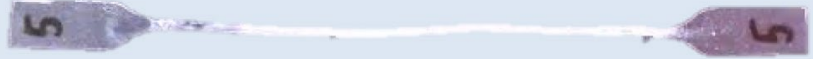

(E)

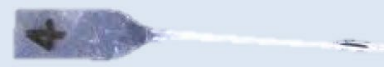

(F)

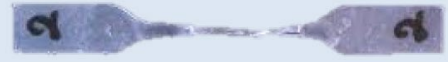

(A) Pre-RPP $210^{\circ} \mathrm{C} 6 \min \mathrm{Q}$, (B) Pre-RPP $210^{\circ} \mathrm{C} 6 \min \mathrm{Q} \rightarrow 210^{\circ} \mathrm{C} 2 \mathrm{~min} \mathrm{SC}$,

(C) Pre-RPP $210^{\circ} \mathrm{C} 6 \mathrm{~min} \mathrm{Q} \rightarrow 65^{\circ} \mathrm{C} 2 \mathrm{~h}$ annealing, (D) Pre-RPP $210^{\circ} \mathrm{C} 6 \mathrm{~min} \mathrm{Q} \rightarrow 65^{\circ} \mathrm{C} 8 \mathrm{~h}$ annealing,

(E) Pre-RPP $210^{\circ} \mathrm{C} 6 \mathrm{~min} \mathrm{Q} \rightarrow 65^{\circ} \mathrm{C} 2 \mathrm{~h}$ annealing $\rightarrow 210^{\circ} \mathrm{C} 2 \mathrm{~min} \mathrm{SC}$,

(F) Pre-RPP $210^{\circ} \mathrm{C} 6 \min \mathrm{Q} \rightarrow 65^{\circ} \mathrm{C} 8 \mathrm{~h}$ annealing $\rightarrow 210^{\circ} \mathrm{C} 2 \mathrm{~min} \mathrm{SC}$ sight of the tensile fracture energy, it was stabilized after performing annealing processing for $2 \mathrm{~h}(\mathrm{E})$. However, it was not stabilized after performing annealing processing for $8 \mathrm{~h}(\mathrm{~F})$.

This result indicates that the annealing conditions must be optimized to stabilize the mechanical properties.

Figure 9 shows a comparison of Young's modulus of the samples. Young's modulus was slightly smaller for the original film (A). However, the values were improved by annealing and re-molding under standard conditions. This means that annealing improves Young's modulus.

Figure 10 shows photo images of the samples after tensile tests. From this figure, the tensile property of original sample has very excellent elongation properties. And simple re-mold without any other processing degrades the mechanical properties; however, the application of suitable annealing treatment could stabilize the enhanced mechanical properties.

\section{Summary}

We evaluated the mechanical properties of thin films of pre-consumer recycled polypropylene that were molded at various temperatures, times and cooling conditions. From the results, by molding higher temperature, longer time and quenching improve the mechanical properties of the recycled polypropylene very much. Especially, quenching after high-temperature molding significantly improves the material properties.
These results indicate that the poor mechanical properties of recycled polymer are mainly due to reversible physical degradation, rather than to irreversible chemical degradation. Also, by choosing the suitable molding conditions, the mechanical properties of recycled polypropylene became almost the same as those of virgin polypropylene. The durability toward UV irradiation was also improved in the mechanically improved samples.

On the other hand, re-molding worsened the improved mechanical properties. This indicates that the inner structure obtained by quenching is not very stable toward heat treatment, i.e., the tie molecules between the lamellar layers formed by the selected molding condition are thermally unstable and significantly decrease during re-molding.

However, by annealing the samples for an appropriate time at a suitable temperature, we can stabilize the mechanical properties.

Acknowledgements This research was supported by the Environment Research and Technology Development Fund (3K143013) of the Ministry of the Environment, Japan.

Open Access This article is distributed under the terms of the Creative Commons Attribution 4.0 International License (http://creativeco mmons.org/licenses/by/4.0/), which permits unrestricted use, distribution, and reproduction in any medium, provided you give appropriate credit to the original author(s) and the source, provide a link to the Creative Commons license, and indicate if changes were made. 


\section{References}

1. Report of Special Research from the National Institute for Environmental Studies (2006) Japan, National Institute for Environmental Studies

2. An Introduction to Plastic Recycling in Japan (2016) Plastic Waste Management Institute, p. 5-7

3. Al-Salem SM et al (2009) Recycling and recovery routes of plastic solid waste (PSW): a review. Waste Manag 29:2625-2643

4. Nishiya Y (2008) Present state of plastic recycling in Japan. Nippon Gomu Kyokaishi 81(9):388-395

5. Yamasue E et al (2010) Evaluation of total materials requirement for the recycling of materials (Urban Ore TMR) from end-of-life electric home appliances. J Jpn Inst Metals 74:811-819

6. Eiichi Takatori T, Shimura T, Adachi S, Yao, Shindou Y (2014) Tensile properties, morphology and rheological properties of a recycled HDPE. J Soc Rheol Jpn 42(1):45-49

7. White EEB, Winter HH, Rothstein JP (2012) Extensional-flowinduced crystallization of isotactic polypropylene. Rheol Acta 51:303-314

8. Binsbergen FL, de Lange BGM (1968) Morphology of polypropylene crystallized from the melt. Polymer 9:23-40

9. Cavallo D et al (2010) Flow memory and stability of shearinduced nucleation precursors in isotactic polypropylene. Macromolecules 43:9394-9400

10. Doufas AK et al (1999) A continuum model for flow-induced crystallization of polymer melts. J Rheol 43:85-109

11. Eiichi Takatori T, Shimura S, Yao, Shindou Y (2014) Dependencies of material properties on averaged molecular weight of a recycled high density polyethylene. J Soc Rheol Jpn 42(1):39-43

12. Hayashi T et al (2009) Precursor of shish-kebab in isotactic polystyrene under shear flow. Polymer 50:2095-2103

13. Housmans JW et al (2009) Saturation of pointlike nuclei and the transition to oriented structures in flow-induced crystallization of isotactic polypropylene. Macromolecules 42:5728-5740

14. Matsuba $\mathrm{G}$ et al (2007) The effects of ultra-high molecular weight components on crystallization under shear flow. Jpn J Polym Sci Technol 64(7):419-428

15. Matsuba G et al (2009) Oriented Structure in Isotactic Polystyrene Melt Induced by Shear Flow. Japanese journal of polymer science technology 66:419-427

16. Ogino $\mathrm{Y}$ et al (2006) Crystallization of isotactic polypropylene under shear flow observed in a wide spatial scale. Macromolecules 39:7617-7625

17. Ogino $\mathrm{Y}$ et al (2006) Effects of high molecular weight component on crystallization of polyethylene under shear flow. Polymer 47:5669-5677
18. Somani RH et al (2006) Thermal stability of shear-induced precursor structures in isotactic polypropylene by rheo-X-ray techniques with couette flow geometry. J Polym Sci Polym Phys 44:3553-3570

19. Zuidema $\mathrm{H}$ et al (2001) Development and validation of a recoverable strain-based model for flow-induced crystallization of polymers. Macromol Theory Simul 10:447-460

20. Hsu Y-C et al (2012) A fundamental study on photo-oxidative degradation of linear low density polyethylene films at embrittlement. Polymer 53:2385-2393

21. Chen HB et al (2002) Fracture toughness $\alpha$ - and $\beta$-phase polypropylene homopolymers and random- and block-copolymers. Polymer 43:6505-6514

22. Tominaga A, Sekiguchi H, Nakano R, Yao S, Takatori E (2015) Thermal process dependence of mechanical properties and inner structure of pre-consumer recycled polypropylene. In: Proceedings of PPS-30, AIP Conf. Proc. 1664, 150011-1-150011-4

23. Tominaga A, Sekiguchi H, Nakano R, Yao S, Takatori E (2013) Advanced recycling technology of pre-consumer waste polypropylene. Jpn J Polym Sci Technol 70(12):712-721

24. Tominaga A, Yao S (2016) Novel recycling technology increases the value of discarded plastic container and packaging resins. Convertech e-Print 6(1):52-57

25. Yao $S$ et al (2013) Inner structure and mechanical properties of recycled polypropylene. J Soc Rheol Jpn 41(3):173-178

26. Yao $S$ et al (2014) UV degradation properties of a virgin/recycled polymer blend. J Soc Rheol Jpn 42(1):61-64

27. Amir S et al (2014) The impact of new crystalline lamellae formation during annealing on the properties of polypropylene based films and membranes. Polymer 55:3156-3167

28. Bai $\mathrm{H}$ et al (2011) New insight on the annealing induced microstructural changes and their roles in the toughening of $\beta$-form polypropylene. Polymer 52:2351-2360

29. Elmoummi A et al (2003) Correlation of material and processing time scales with structure development in isotactic polypropylene crystallization. Macromolecules 36:6453-6461

30. Ferrer-Balas D et al (2011) Influence of annealing on the microstructural, tensile and fracture properties of polypropylene films. Polymer 42:1697-1705

31. Hedesiu $\mathrm{C}$ et al (2007) The effect of temperature and annealing on the phase composition, molecular mobility and the thickness of domains in high-density polyethylene. Polymer 48:763-777

32. Maxwell AS et al (1996) The effect of high pressure annealing on the molecular network in polyethylene. Polymer 37(15):3293-3301 